\section{Revisitando a geração de 1870}

Angela ALONSO. Idéias em movimento: a geração 1870 na crise do Brasil-Império. São Paulo, Paz e Terra, 2002. 392 páginas.

Eduardo Kugelmas

Duas abordagens ocupam tanto espaço na bibliografia existente sobre o movimento intelectual dos últimos lustros do período imperial que podem ser consideradas arquetípicas. Uma enfatiza as linhagens intelectuais, debatendo as influências filosóficas e culturais do mundo metropolitano, especialmente a Europa. Os autores e os grupos tendem a ser classificados pelo impacto em suas obras das principais correntes da época, como positivismo, evolucionismo e cientificismo. A sempre lembrada expressão de Sílvio Romero - o "esvoaçar de idéias novas" - baliza as discussões em torno da filiação intelectual dos autores e do maior ou menor grau de originalidade nas formas de adoção dos paradigmas mais correntes. Outro tema recorrente é o da formação das "escolas", que debatem e polemizam entre si. Já a segunda linha enfatiza a origem social dos participantes do debate intelectual, apresentando seus protagonistas como porta-vozes de setores médios da sociedade, ou de uma burguesia urbana nascente, crítica das instituições imperiais e do sistema socioeconômico baseado na escravidão.

Ambos esses prismas são questionados em Idéias em movimento, desdobramento de tese de doutorado apresentada no departamento de Sociologia da USP e premiada pela Anpocs. Para a jovem autora, ao primeiro dos enfoques falta contextualização social e política, e ao segundo sobra simplismo na busca da caracterização da produção intelectual da época, vista como expressão ideológica imediata dos interesses de grupos desconformes com o universo político e cultural do Império. Mais do que uma história das idéias, este notável e original esforço de pesquisa vai constituir uma sociologia do pensamento, na tradição de Karl Mannheim. O tratamento dado ao tema contesta incisivamente alguns pressupostos implícitos das abordagens tradicionais, tais como a suposição da existência no Brasil de então de um campo intelectual autônomo, nitidamente distinto da esfera política, e também o vezo de muitos intérpretes a aceitar de forma acrítica os juízos e as opiniões dos autores da época sobre seu próprio papel.

Para fundamentar sua alternativa, Angela Alonso reexamina um dos problemas clássicos das ciências sociais, o da natureza da interação entre práticas sociais e construções intelectuais, entre as bases materiais e o campo ideológico. Rejeitando dois tipos de reducionismo, o cognitivo e o prático, traz para o centro de sua investigação a questão de como se vinculam cultura e experiência. Tomando como referência os estudos de Pierre Rosanvallon sobre a França na época da monarquia orleanista e de Charles Hale sobre o México no período de Porfirio Diaz, a autora enfatiza a experiência social compartilhada pelos membros da geração de 1870, analisando suas manifestações intelectuais como formas de atuação política. Apesar da heterogeneidade de pontos de vista, da diversidade das formas de metabolização dos temas doutrinários e das polêmicas entre os diversos grupos, uma referência comum legitima o uso da expressão "geração". O que os une é a perspectiva crítica ante o status quo da sociedade imperial, sua situação de relativa marginalização em face do núcleo de poder constituído pelos saquaremas conservadores infensos a quaisquer mudanças - e, como corolário, o papel por eles desempenhado de paladinos de propostas reformistas.

Para sua construção analítica, a autora baseia-se no conceito de estrutura de oportunidades políticas desenvolvido por Sidney Tarrow, referindo-se a conjunturas de crise que incentivam movimentos coletivos. Os sintomas visíveis de desagregação da ordem política imperial, incapaz de enfrentar os desafios da modernização incompleta do país, atestam a existência de uma crise dessa natureza. Para enfrentar essa situação, os jovens que ambicionavam carreiras públicas ou projeção intelectual, desígnios que na época facilmente se confundiam, lançavam mão do que consideravam inovador e pertinente no redemoinho de idéias 
do universo europeu. Esse tipo de apropriação é examinado por Angela Alonso como um exemplo de repertório, na acepção dada ao termo por Charles Tilly e Ann Swindler, ou seja, conjunto de recursos políticos e intelectuais utilizados como ferramentas para compreender uma determinada realidade e intervir sobre ela.

Após o bem-sucedido esforço do gabinete conservador de Rio Branco (1871-1875) em desenvolver um programa de reformas moderadas, a vida política tem como leit motif a resistência à mudança, sendo adiada para as calendas gregas a extinção do escravismo, diluídas as propostas de reforma política e reafirmado o catolicismo como religião do Estado. A velha disputa entre os partidos esvazia-se cada vez mais, o bem-sucedido reformismo de Rio Branco, que teria "roubado as bandeiras" dos liberais, deixa a estes pouco espaço de atuação e sua volta ao governo em 1878 com o gabinete Sinimbu não será mais do que uma manifestação de força do poder Moderador, tornando letra morta suas antigas veleidades de crítica mais profunda ao quadro institucional.

A mobilização intelectual da geração de 1870 deve ser vista como parte da tão conhecida efervescência social e política que marca o período, extravasando o sistema dominante. O partido Republicano ganha força, sobretudo na Corte, em São Paulo e no Rio grande do Sul, estrutura-se o movimento abolicionista e há sinais de inquietação entre os militares. Após descrever e analisar a crise da ordem imperial no primeiro capítulo, a autora chega ao cerne de sua problemática ao apresentar, no segundo capítulo, "a ordem contestada”, sua visão da geração de 1870 e dos distintos grupos que a integraram. Apontando a heterogeneidade das origens sociais de seus membros, que incluíam tanto setores em ascensão como outros estacionários e mesmo decadentes, Alonso examina o que ocorreu na época como um conjunto de manifestações de setores distintos, mas que tinham em comum uma situação de relativa marginalização diante da estrutura de poder político vigente.

Rompendo com as tentativas de classificação baseadas na adesão a matrizes intelectuais européias, a autora baseia-se em um levantamento mi- nucioso da trajetória política e intelectual de 120 participantes dos debates da época e sugere a existência de cinco agrupamentos: novos liberais, liberais republicanos, positivistas abolicionistas, federalistas positivistas gaúchos e federalistas científicos paulistas.

Joaquim Nabuco e André Rebouças foram as figuras mais expressivas dos novos liberais. Como filhos de destacados membros da elite imperial e tendo acesso fácil à família real, eram marginais apenas porque se mantinham à distância do núcleo saquarema. Distinguem-se dos outros grupos pela fidelidade às instituições monárquicas, já que vislumbravam um impulso reformista "pelo alto", ou seja, formulado no interior da própria elite. Como plataforma central de reformas, propunham a abolição da escravatura e a modernização econômica, chegando, no caso de Rebouças, à crítica explícita do sistema agrário baseado na grande propriedade. Para eles a República não seria uma solução, mas uma ameaça à unidade nacional. Ao longo da década de 1880, oscilaram entre a participação política por meio do velho partido Liberal e pelo engajamento na campanha abolicionista. Nos últimos meses do regime, defenderam a tese da monarquia federativa, e Ruy Barbosa, um dos seus ativistas, torna-se o mais combativo representante desta tese.

Quintino Bocaiúva foi personagem emblemático dos liberais republicanos, grupo oriundo da radicalização de parte dos liberais e que teve como padrinho o senador liberal convertido em defensor do republicanismo, Saldanha Marinho. Co-autor do manifesto republicano de $1870 \mathrm{com}$ Salvador da Mendonça, Bocaiúva era um dos jornalistas mais atuantes da época. Esse setor tinha um forte enraizamento no Rio de Janeiro e na opinião pública urbana, defendia a descentralização federativa e a ampliação do sistema representativo, sendo contemporizadores com relação à abolição. Seus membros atuavam por vezes como uma facção a mais do partido Liberal, sendo moderadíssimos em suas plataformas.

Os positivistas abolicionistas, como Miguel Lemos, fundador do Apostolado Positivista do Rio de Janeiro, tinham como referência ideológica central a divulgação sistemática do pensamento 
de Auguste Comte e de seu sucessor Pierre Laffitte. Eles consideravam a escravidão e a monarquia sobrevivências anacrônicas de estágios anteriores da evolução das sociedades. Recrutaram muitos de seus adeptos entre os egressos e estudantes de Engenharia, inclusive os alunos de Benjamim Constant na Escola Militar. Estes eram freqüentemente de origem mais humilde do que os membros típicos da elite imperial e foram se constituindo como o núcleo de questionamento do regime nas fileiras do Exército. Em um de seus momentos mais polêmicos, a autora, que questiona a existência de uma "Escola do Recife", apresenta Tobias Barreto e Sílvio Romero como um desdobramento nordestino desse grupo, embora sua prática política fosse próxima aos liberais republicanos e seus escritos carregassem mais nas tintas evolucionistas do que na pregação comteana de caráter "puro" pretendida pelo Apostolado.

É a dimensão regional que caracteriza os dois últimos agrupamentos - federalistas positivistas do Rio Grande do Sul e federalistas científicos de São Paulo. Seu alvo político é a descentralização político-administrativa, entendida como reivindicação de autonomia para as respectivas províncias. Em São Paulo, identificam-se com a camada em ascensão dos cafeicultores do próspero Oeste da província. Luis Pereira Barreto e Alberto Sales utilizaram as ferramentas do pensamento positivista e da política científica para justificar um "paulistismo" que conjugava a ânsia pela modernização econômica e técnica com a plataforma republicana e federativa. O grupo gaúcho defendia de forma elaborada uma plataforma análoga, tendo Assis Brasil e Júlio de Castilhos como seus principais representantes.

Quais os laços que uniram as plataformas desses grupos díspares? Para a autora, o fio condutor foi a utilização, como ferramentas, de elementos disponíveis no movimento das idéias da época, que serviam de base tanto para fundamentar um diagnóstico de crise como para o conjunto de propostas reformistas. Alonso insiste no escasso valor heurístico de explicações baseadas na idéia de importação de modelos, já que positivismo, evolucionismo, cientificismo e darwinismo eram instrumentos culturais que lastreavam as propostas de mudança. E também, com razão, ressalta um ponto por vezes esquecido, qual seja, a tentativa de reexame crítico da história do país presente nesse conjunto de obras, demonstrando uma interação entre as "idéias européias" e a construção de uma visão própria.

O livro de Angela Alonso é um trabalho de fôlego, caracterizado por maturidade e ousadia inovadora. Poder-se-ia levantar uma dúvida: não levaria esta interpretação voltada para os laços comuns entre as várias tendências à subestimação de algumas de suas especificidades? Os novos liberais que conciliaram uma crítica social aguda com a defesa da monarquia não mereceriam um lugar aparte? Essas questões talvez possam ser respondidas em novos estudos, dando continuidade a essa tão promissora redescoberta da história do pensamento político e social brasileiro que, felizmente, vem atraindo o olhar de excelentes jovens pesquisadores.

\section{EDUARDO KUGELMAS é professor do depar- tamento de Ciência Política da USP e pesqui- sador do CEDEC - Centro de Estudos de Cultura Contemporânea.}

